\title{
Carinal resection
}

\author{
Roman V. Petrov, Charles T. Bakhos, Abbas E. Abbas \\ Department of Thoracic Medicine and Surgery, Lewis Katz School of Medicine at Temple University, Philadelphia, PA, USA \\ Contributions: (I) Conception and design: All authors; (II) Administrative support: None; (III) Provision of study material or patients: None; (IV) \\ Collection and assembly of data: None; (V) Data analysis and interpretation: All authors; (VI) Manuscript writing: All authors; (VII) Final approval of \\ manuscript: All authors. \\ Correspondence to: Roman V. Petrov, MD, PhD, FACS. Assistant Professor, Department of Thoracic Medicine and Surgery, Lewis Katz School of \\ Medicine at Temple University, Philadelphia, PA, USA. Email: roman.petrov@tuhs.temple.edu.
}

\begin{abstract}
Tracheobronchial tumors with involvement of the carina represent a challenging problem in the pulmonary surgery. Carinal resection is referred to removal and reconstruction of the airway itself, whereas concomitant removal of the lung parenchyma (usually a whole lung) is termed as carinal pneumonectomy. Thorough preoperative workup of these patients is mandatory. Meticulous surgical technique and aggressive postoperative management is required for the best outcomes in these difficult cases. In the paper authors review surgical technique, evaluation and management of this challenging patient population.
\end{abstract}

Keywords: Tracheobronchial tumors; tracheobronchial resection; carinal resection; carinal reconstruction; carinal pneumonectomy; tracheobronchial anastomosis

Received: 20 April 2018; Accepted: 18 October 2018; Published: 02 November 2018.

doi: $10.21037 /$ shc.2018.10.03

View this article at: http://dx.doi.org/10.21037/shc.2018.10.03

\section{Introduction}

Carinal resection is a challenging problem from technical aspects of the procedure itself, preoperative patient selection and postoperative management. This type of resection most commonly performed for malignancy. Resection can include just the airway itself (carinal resection) or encompass parenchymal resection, usually the whole lung, and then it referred to as "carinal pneumonectomy". Under any circumstances, meticulous attention to details in carinal reconstruction is necessary for restoration of airway continuity. Different types of neo carinal reconstruction are described. Postoperatively these patients require vigorous management with aggressive pulmonary toilet and liberal use of bronchoscopy for airway clearance.

\section{Preoperative evaluation}

\section{Staging workup}

Primary tracheal tumors are very rare entity with an incidence of 0.1 per 100,000 of population. Metastatic lesions to the trachea are also rare. Tracheal involvement by contiguous extension of malignancy from nearby structures (lungs, larynx, thyroid) is more prevalent. Squamous cell carcinoma and adenoid cystic carcinoma comprise the $60-80 \%$ majority of primary tracheal tumors. The rest is represented by a heterogenous group of benign and malignant tumors (1). Most of the carinal resection are performed for bronchogenic malignancy. Benign diseases of the trachea and bronchi, requiring carinal resection constitute a minority of cases (2-7).

Due to its rarity, there is no separate TNM classification of the primary tracheal tumors. Several proposed classifications have not been validated, however involvement of the mediastinal lymph nodes is considered stage IV and is associated with poor prognosis $(8,9)$. Induction therapy for locally advanced tracheal tumors is uncommon and rarely reported in the literature (10).

Thorough preoperative evaluation and staging of the patients is required for selection of the appropriate candidates (2-4).

Patient with trachea-bronchial malignancies present with chronic nonproductive cough. Production of sputum frequently is associated with post obstructive pneumonia 
and tracheobronchitis and will require drainage and antibiotic therapy. Some patients develop hemoptysis that is usually minimal. Stridor may be present in patient with high grade airway obstruction and those represent true emergency.

Computed tomography of chest frequently is a first study that reveals presence of the lesion at the distal trachea and main bronchi. It allows assessment of the primary tumor extent, status of mediastinal lymph nodes, condition of the pulmonary parenchyma and presence of pleural or pericardial effusion.

Bronchoscopy is an initial diagnostic and potentially therapeutic intervention. It allows direct visualization of the lesion, assessment of its extent and tissue acquisition for pathological examination. In cases of obstructing lesions, endoluminal palliation techniques can be employed for lumen restoration. Cryoablation with cryospray or cryoprobe can be used. The later allows mechanical tumor debulking. Laser or argon plasma ablation can be utilized for tumor vaporization. Finally, brachytherapy or photodynamic therapy can be used. Sometimes temporary stenting can be utilized to reestablish the airway lumen, although generally, stents cause mucosal irritation, granulation and even peribronchitis and can make subsequent resection more challenging $(7,11,12)$.

Rigid bronchoscopy allows coring out of the lesion for luminal restoration. Although this modality is falling out of favor nowadays due to rise of new advanced fiberoptic endoluminal techniques, it is proved invaluable in difficult cases $(13,14)$.

Reestablishing of the lumen provides time to complete appropriate staging and prehabilitate patient prior to surgery. In cases of post obstructive pneumonias, it allows for the drainage and resolution of the infection in combination with antibiotic therapy $(13,14)$.

Position emission tomography is an important staging modality that aids in assessment of the primary tracheal malignancy, mediastinal and distant metastases, presence of which would require tissue diagnosis (15).

Generally, brain imaging is indicated in patient with neurogenic symptoms, central lesions, large tumors or presence of metastatic disease. As such, all patients with carinal involvement will require evaluation of the central nervous system for the presence of metastatic disease.

Magnetic resonance imaging can better delineate extent of the tracheal tumors into peritracheal tissues and vascular anatomy (16).

Endobronchial ultrasound (EBUS) is a valuable tool in the evaluation of such lesions. Presence of mediastinal nodal disease is an important predictor of poor survival after complex lung resections (17-19). As such, invasive mediastinal staging is required for evaluation of mediastinal lymph nodes. Disruption of the anterior pretracheal plane during mediastinoscopy will lead to scarring and decreased tracheal mobility, increasing tension and limiting extent of the subsequent resection and potentially increasing anastomotic complications. As such, preoperative mediastinoscopy is not recommended. EBUS allows adequate sampling of the mediastinal LNs for the purposes of the pathologic evaluation (20).

Pulmonary function tests are required for assessment of the pulmonary reserve and aid in decision making of medical operability of the patient.

Considering common risk factors, such as age and smoking exposure, many patients with lung cancer will harbor coronary disease. Thorough cardiac evaluation with ischemic workup is usually necessary in these patients. That at least should include cardiac stress test.

Patients, in whom carinal pneumonectomy is contemplated, should undergo quantitative VQ scan to better delineate predicted postoperative pulmonary function. Critical appraisal of test results is required prior to resection, as partial or complete airway obstruction may render disappointing outcomes. Either restoration of luminal patency via endobronchial modalities or adjustment for compromised segments is required. SPECT/VQ is an emerging imaging modality, allowing precise delineation of functional lung anatomy and may prove useful in these circumstances (21).

Echocardiography in these patients would identify high risk group of individuals with pulmonary hypertension. It is important to keep in mind that transthoracic echo tends to overestimate degree of pulmonary hypertension and if questions remain, right heart catheterization may be required.

6 min walk test can provide overall assessment of the patent physiologic status. Formal cardiopulmonary exercise testing may be ultimately necessary to select patients that would be good candidates for resection. Recently, assessment of the frailty was regarded as an important part of the preoperative evaluation (22).

\section{Anesthesia consideration and airway management}

Shared responsibility of the airway between an anesthesiologist and a surgeon requires constant and clear 


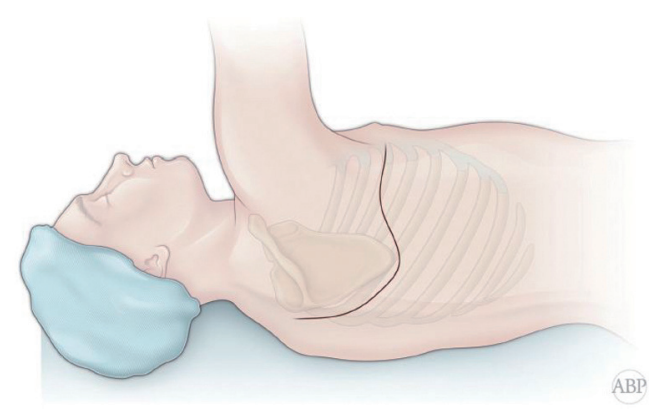

Figure 1 Posterior lateral thoracotomy for carinal resection. Please note curvilinear encircling of the scapular tip due to fourth interspace access.

communication of all steps of the procedure in cases of airway surgery.

The mainstay of pulmonary isolation during thoracic procedures-the double lumen tubes are not useful during carinal resection due to their bulkiness and difficulties in manipulating (2).

Usually the single lumen tube that is advanced into left main bronchus, provides good right lung isolation and can be repositioned during the time resection. Many authors prefer armored tube to prevent its kinking $(6,18,23)$.

Division of the central airway will require distal lung ventilation. It can be accomplished with cross field ventilation with sterile tubing set up. This tube can be used to intermittently ventilate the lung, alternating with periods of apnea, when tube is removed to allow suture application $(3,4)$.

Alternatively, jet ventilation to the lung can be performed via small bore tubes (IV or suction tubing). However, that usually causes pulverization of blood and mucous in the field and not met with enthusiasm by many surgeons. Benefits include smaller diameter catheter that allows easier placement of the sutures around it without need for removal. This catheter can be inserted via the lumen of the endotracheal tube and be advanced into the left lung $(24,25)$. Use of two catheters has been described for dual lung ventilation (26).

Continuous oxygen insufflation into the lung via a small catheter without ventilation can allow oxygenation in prolonged episodes of apnea to perform application of anastomotic sutures. Nonintubated carinal resection and reconstruction has been described utilizing VATS approach with spontaneous breathing (27).

In patient with poor pulmonary function extracorporeal lung support can be utilized. Low flow VV ECMO, full flow VV and VA ECMO and full CPB has been described in small series and case reports (28-32). It has, however, been associated with increased risk of bleeding complications $(2,6)$.

\section{Surgical management}

\section{Intraoperative planning}

Bronchoscopy is routinely performed prior to resection. Direct visualization allows for final assessment of the anatomy and decision on the resectability. Usually up to $4.5 \mathrm{~cm}$ of the airway can be safely resected without undue tension. Bigger defects are prone to such devastating complication as dehiscence and alternative plans have to be made. In some authors opinions up to $7 \mathrm{~cm}$ of resection can be bridged with use of release maneuvers (33). Negative resection margins are associated with better outcomes. As such surgeons, performing bronchoscopic assessment need to be familiar with endoscopic picture of submucosal tumor spread, like corrugated surface, dilated mucosal vessels, mucosal edema and others. Narrow band imaging and indocyanine green (ICG) can help with the assessment of the tumor extent and anastomosis perfusion $(34,35)$. If it is determined that safe resection is not possible, such patients need referral for definitive radiation therapy. Sometimes final decision on the resectability is made during surgical exploration $(2,17,23)$.

Mediastinoscopy immediately prior to resection is recommended for the development of the pretracheal plane to aid in the tracheal mobilization. It is important to remember that blood supply to the trachea comes from the lateral segmental vessels and their preservation is important for successful postoperative healing $(2,36)$.

\section{Surgical approaches}

\section{Right thoracotomy}

Majority of the carinal resections and reconstructions and right carinal pneumonectomy can be performed though right posterior lateral thoracotomy. Entrance to the pleural cavity is gained in fourth interspace (Figure 1). Lung is retracted anteriorly and inferiorly. Azygos vein is divided. Mediastinal pleural is opened anterior to the esophagus. Sometimes mobilization and posterior retraction of the esophagus might be required. At this point, distal trachea with right main bronchus is exposed. Circumferential mobilization of the carina will lead to adequate exposure for intraoperative assessment and manipulation (Figure 2) $(2,4,18)$. 


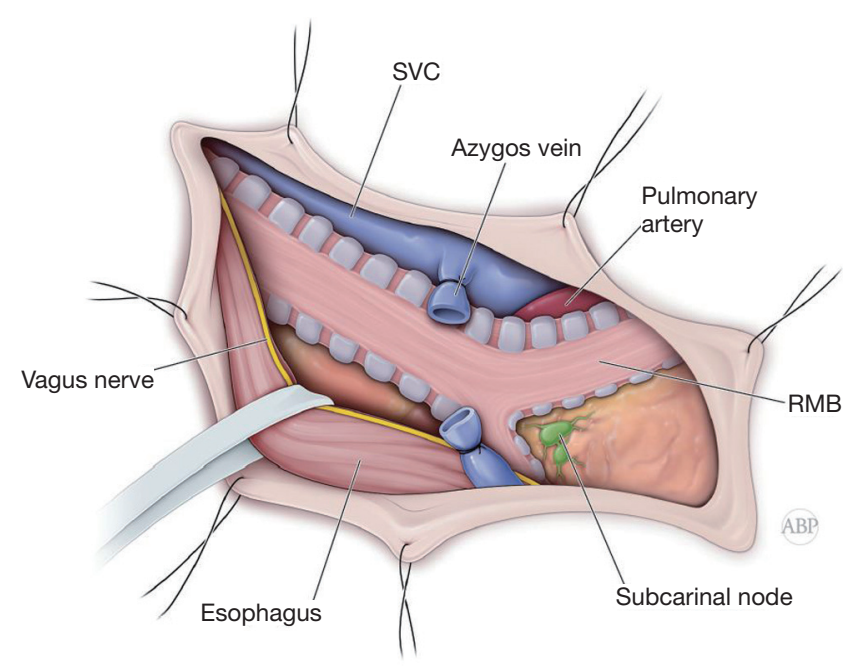

Figure 2 View of the distal tracheal and carina through right thoracotomy approach.

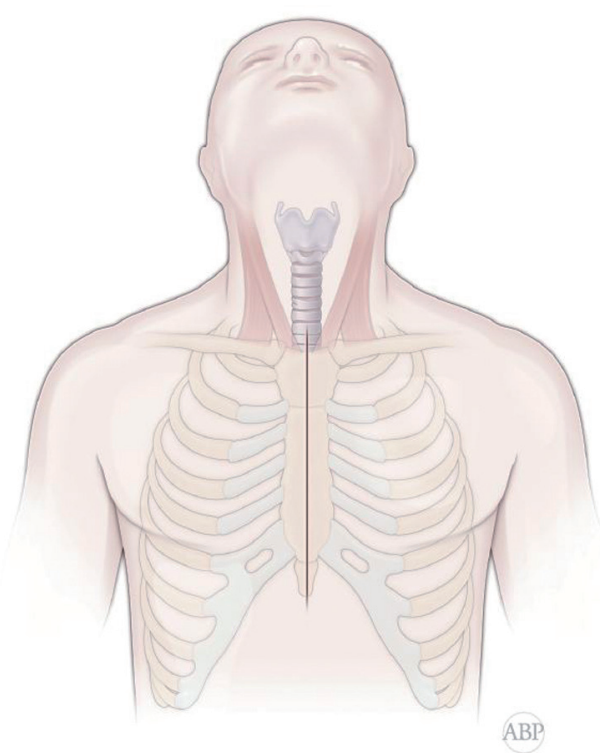

Figure 3 Median sternotomy for the anterior approach to the carina.

\section{Left thoracotomy}

Left thoracotomy is not a very robust approach to the carina. Arch of the aorta and length of the left main bronchus produce a deep field, limiting exposure of the carina and trachea. This approach can be sparingly applied for the cases of predominantly left main bronchus lesions with limited involvement of the carina itself. If left sided approach is chosen, mobilization of the aorta and left

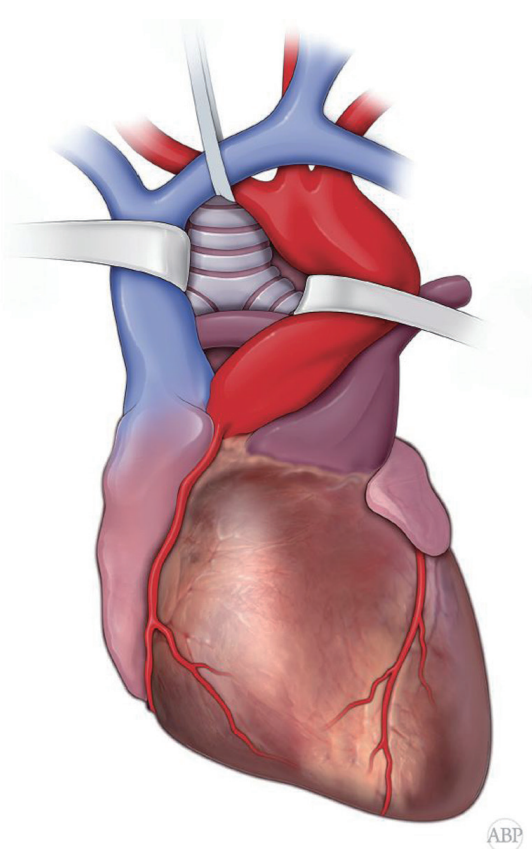

Figure 4 View of the carina from the anterior approach.

pulmonary artery will improve the exposure (2).

\section{Median sternotomy}

Anterior approach via sternotomy is useful for isolated carinal resection and reconstruction. It is also used for left carinal pneumonectomy (Figure 3). This anterior approach can also be accomplished via "clamshell" incision.

Once sternum is divided, anterior pericardium is incised. Space between SVC and ascending aorta developed and these vessels encircled with umbilical tapes and retracted apart. Also, cranial mobilization of the brachio-cephalic vessels and right pulmonary artery in the caudal direction is carried (Figure 4). At this point, incision of the posterior pericardium exposes distal trachea and carina. However, dissection and manipulation of the structures in this tight space can be somewhat limited $(2,4,23)$.

\section{VATS}

Minimally invasive approach is described for carinal resection and reconstruction. Procedure is performed via right chest. Access incision is placed in the fourth interspace. Dissection is carried to mobilize distal trachea and carina, with the anatomic relations similar to right thoracotomy view. Trachea is transected under bronchoscopic control and bronchi are divided under direct visualization. Distal lung ventilation can be achieved either through cross field setup, 


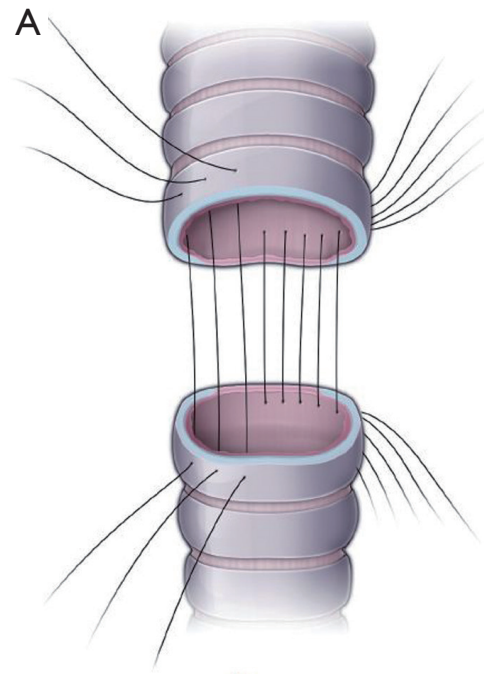

B

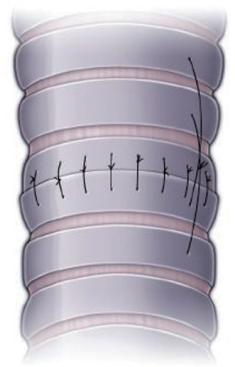

Figure 5 Tracheobronchial anastomosis with interrupted sutures.

A
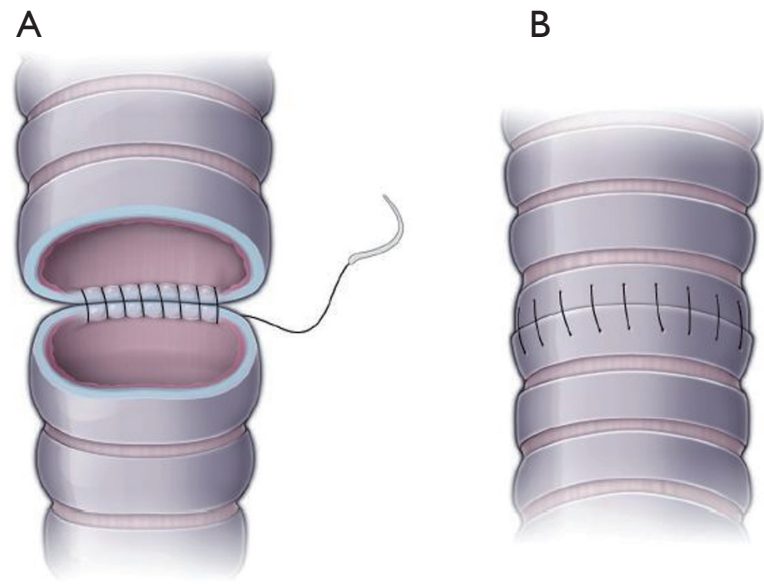

$\mathrm{ABP}$

Figure 6 Tracheobronchial anastomosis with continuous running stitch.

advancing endotracheal tube though a separate incision in the second interspace or jet ventilation via small catheter, advanced through the endotracheal tube lumen $(27,37)$.

\section{Other approaches}

Trap-door, Dartevelle incision and anterior thoracosternotomy (clamshell) incision have been previously described for the carinal resection and reconstruction. However, they rarely employed nowadays $(2,23)$.

\section{Tracheobronchial anastomosis}

Classically, in open procedures, anastomosis is performed with simple interrupted absorbable sutures (4-0 Vycril). With bronchoscopic view, transmural finder needle probing is used to clearly identify proximal level of resection. Wrong level will result in longer defect and either compromised distal margin or higher tension on the anastomosis. Once trachea is transected above the tumor, distal end of the trachea is delivered into the wound. At this point under direct visual control distal division of the airway is performed and specimen is retrieved and sent for frozen section for margins. Cross table ventilation instituted by intubating the distal airway. 2-0 Vicryl retention sutures applied at the tracheal and bronchial ends. At this point 4-0 Vicryl interrupted sutures placed circumferentially approximately $4 \mathrm{~mm}$ apart and deep (Figure 5A). Sutures are organized by clipping to the drape in order or GabbayFrater suture organizer can be used. Size mismatch should be approximated by wider suture spacing on the tracheal end. Beveling of the bronchial end is not recommended for the risk of the tip ischemia and dehiscence. Once all sutures applied, cross table tube is removed and endotracheal tube is advanced into the distal airway. 2-0 retention sutures are tied to bring edges together and all sutures are tied (Figure 5B).

During minimally invasive, either VATS or robotic carinal resections, airway anastomosis usually performed with continuous running stitch (Figure 6A,B) (37-40). Recently unidirectional barbed stitch use has been described for the bronchial anastomosis (41-43). This technique is also finding its way into open procedures as well.

\section{Carinal resection $v s$. carinal pneumonectomy}

In cases of carinal resection, with only airway removed with preservation of both lungs, different types of reconstruction are required to recreate bifurcating nature of the carina. These types of resection sometimes can include sleeve lobectomies, mostly on the right side, with subsequent reconstruction of the neocarina.

In cases of carinal pneumonectomy one of the lungs is removed with the airway resection and reconstruction with single anastomosis between distal trachea and proximal end of the main bronchus.

\section{Right carinal pneumonectomy}

Approach is via right thoracotomy or sternotomy. After exposure of the distal trachea and carina, endotracheal tube is pulled back. Trachea is transected. Distal level of resection is verified under direct visual control. Left main bronchus is intubated with small endotracheal tube and cross field ventilation is instituted. Anastomosis is performed in the described fashion between the distal 


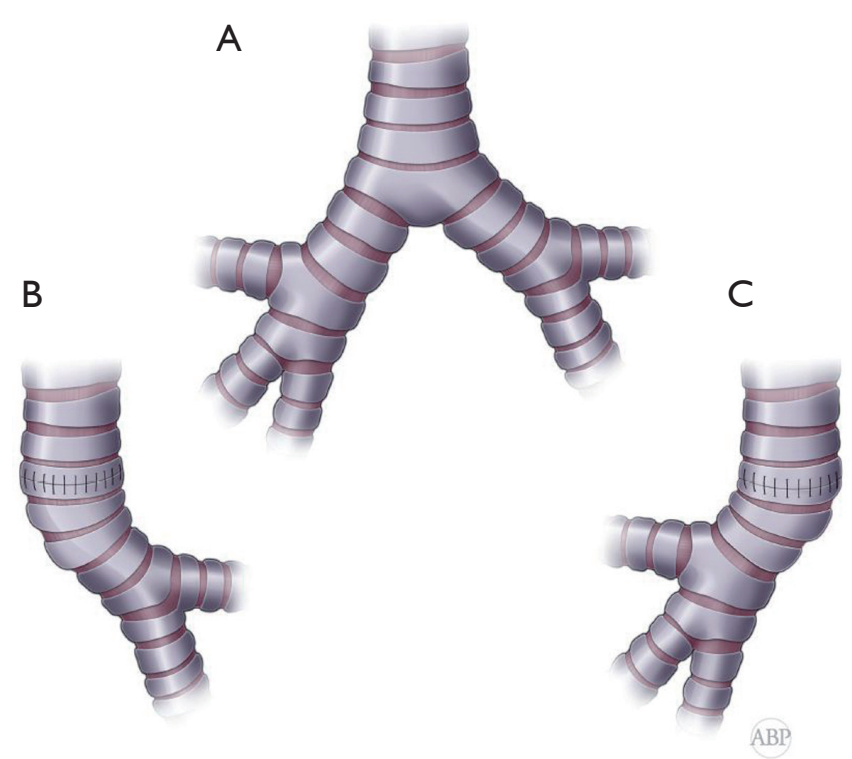

Figure 7 Tracheobronchial reconstruction after carinal pneumonectomy. (A) Normal anatomy; (B) right carinal pneumonectomy; (C) left carinal pneumonectomy.

trachea and the left main stem bronchus. Prior to closure of the sutures, cross-filed tube is removed, airway is suctioned out and endotracheal tube is advanced into the left main bronchus (Figure $7 A, B)(2,44)$.

\section{Left carinal pneumonectomy}

Approach is via median sternotomy. After adequate exposure and retraction of the endotracheal tube, proximal tracheal division is performed under bronchoscopic control. Right main bronchus is divided under direct vision and distal lung is ventilated with cross field circuit. Left pneumonectomy is accomplished in the left chest by division of the left pulmonary artery and veins and specimen is retrieved. After removal of cross-filed circuit edges of airway approximated with traction ligatures and sutures are tied, completing the anastomosis (Figure $7 A, C)(18,23)$.

\section{Types of carinal reconstruction}

Approach to carinal reconstruction largely depends on the individual anatomy and extent of the resection.

In cases of sufficient length of both main bronchi they can be sewn side to side together at the medial wall to recreate neocarina and then be anastomosed to the distal trachea at the same level (Figure 8A,B) $(2,6,23)$.

When one of the bronchi is substantially longer, bronchial reconstruction with different levels of anastomoses can be utilized. Usually, the longer bronchus can be anastomosed to the tracheal end and the shorter bronchus implanted end to the side the contralateral bronchus. Opening on the side of the bronchus should be placed within cartilaginous portion of the bronchial wall for added strength and security (Figure 8A,C,D). Occasionally, the shorter bronchus, in case of sufficient length, can be anastomosed to the tracheal end and the longer bronchus implanted in the end to side fashion to the side of the trachea, creating tracheobronchial anastomosis (Figure $8 A, E, F)(2,23)$. This modification potentially decreases tension on the tracheal anastomosis.

With multi-leveled carinal reconstruction with multiple anastomoses, at least $1 \mathrm{~cm}$ bridge of intact tissue should be kept between the suture lines.

After completion of all anastomoses, they are tested with positive pressure ventilation to assure their competency and absence of the airleak.

\section{Release maneuvers}

Creating anastomosis under tension increases risk of complications in tracheobronchial surgery. Release maneuvers provide additional mobilization, advancing the airway edges, allowing greater extent of resection and tension free anastomosis.

\section{Pretracheal plain development}

It is usually performed during intraoperative mediastinoscopy. It can also be accomplished with digital dissection through the surgical field from right thoracotomy or sternotomy (reverse mediastinoscopy). Interference with lateral blood supply should be avoided to prevent devascularization of the trachea $(36,45)$.

\section{Neck flexion}

Intraoperative neck flexion by the anesthesiologist descends larynx caudally and provides one to two centimeters of the distal tracheal advancement $(23,46,47)$.

\section{Inferior hilar release}

U-shape pericardiotomy around inferior pulmonary vein on the right allows cranial advancement of the right main bronchus by one to two centimeters. Even more mobility can be achieved by complete hilar release with circumferential pericardiotomy around both pulmonary veins. Hilar release is rarely performed on the left side as aortic arch prevents significant left main bronchial advancement $(33,45)$.

\section{Hyoid release}

Rarely results in additional mobility at the carinal level and is not utilized $(33,45)$.

\section{Division of the Batali ligament}

Separation of the pulmonary artery from aortic arch 

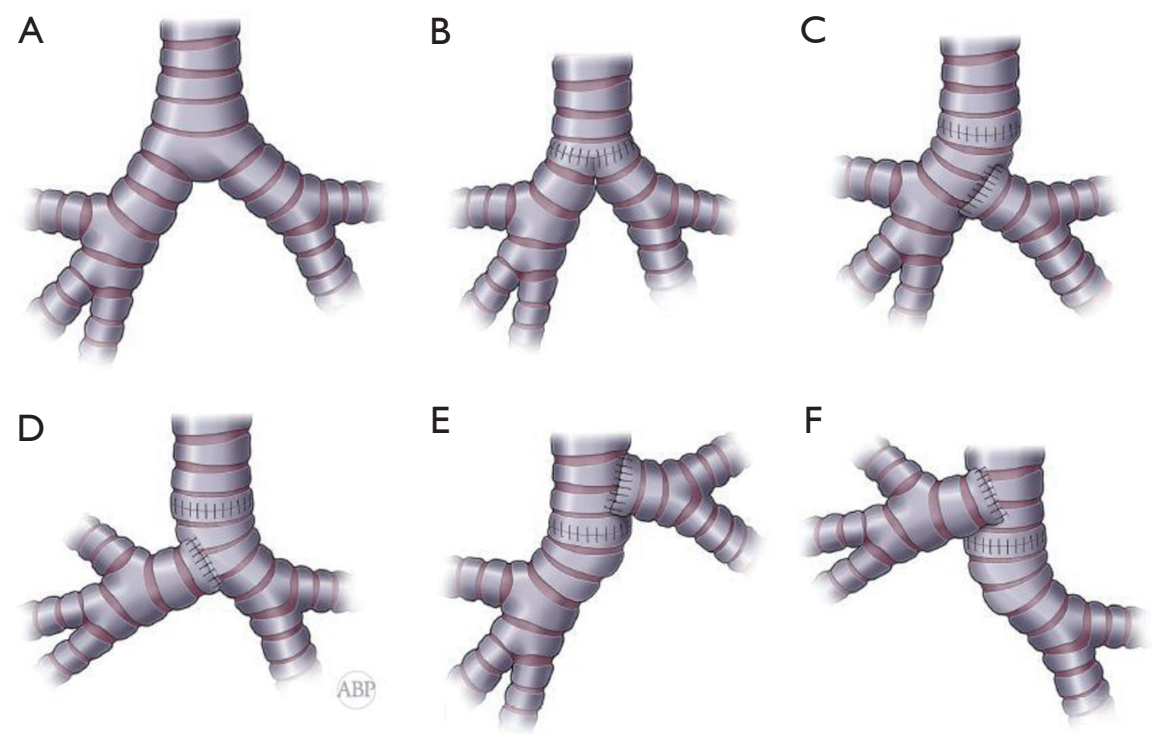

Figure 8 Tracheobronchial reconstruction after carinal resection. (A) Normal anatomy; (B) bifurcating anastomosis of both main bronchus to the distal trachea; (C) anastomosis of trachea to the right main bronchus with implantation of the left main bronchus to the side of the right main bronchus; (D) anastomosis of trachea to the left main bronchus with implantation of the right main bronchus to the side of the left main bronchus; (E) anastomosis of the trachea to the right main bronchus with implantation of the left main bronchus to the side of the trachea; (F) anastomosis of trachea to the left main bronchus with implantation of the right main bronchus to the side of the trachea.

by division of the ligamentum arteriosum can provide additional mobility of the left main bronchus (33).

\section{Left main bronchus release}

Is achieved by mobilization of the left main bronchus by digital plane development on the ventral surface of the bronchus under the aortic arch $(2,36)$.

\section{Pericardiophrenic release}

Separation of the pericardium from the diaphragm is performed with electrocautery between two phrenic nerves. It aids to the hilar release and adds additional $2-3 \mathrm{~cm}(10)$.

\section{Vascularized tissue flaps}

Bronchial blood supply forms plexus in the peribronchial tissue, drawing blood from bronchial arteries, branches of subclavian, internal mammary, brachiocephalic, coronary vessels, thoracic aorta and intercostal vessels. Preservation of the airway blood supply is one of the tenets of the airway surgery. Circumferential airway mobilization with interruption of the lateral blood supply should not extend few millimeters beyond the level of transection $(46,48)$.

Anastomotic dehiscence is a fearful complication of the airway surgery, associated with high morbidity and mortality. Vascularized tissue flaps are utilized to prevent anastomotic dehiscence. Pericardial, pleural and thymic fat are local flaps that can be employed for these purposes. Intercostal muscle flaps are also used with good success. Omental and extrathoracic muscle flaps have been described as well and mostly used for bringing vascularized tissue in cases of neoadjuvant radiation (49-53).

\section{Challenging scenarios}

\section{Long segment tracheal resection and reconstruction and tracheal replacement}

Extended resections of the trachea are limited due to lack of acceptable replacement conduit. Multitude of the described options prove lack of the acceptable universal solution. Local and muscle flaps, autogenous vascular and tracheal grafts are described for the replacement of the large tracheal defect $(50,54,55)$. Use of the forearm free fasciocutaneous flap with rib cartilages reinforcement was described in eight patients. That allowed resection of large lesions with defects of up to $12 \mathrm{~cm}$ (56). Experimental models of three-dimensional printed grafts and tissue engineered tracheal scaffolds are under investigation (57-59). 


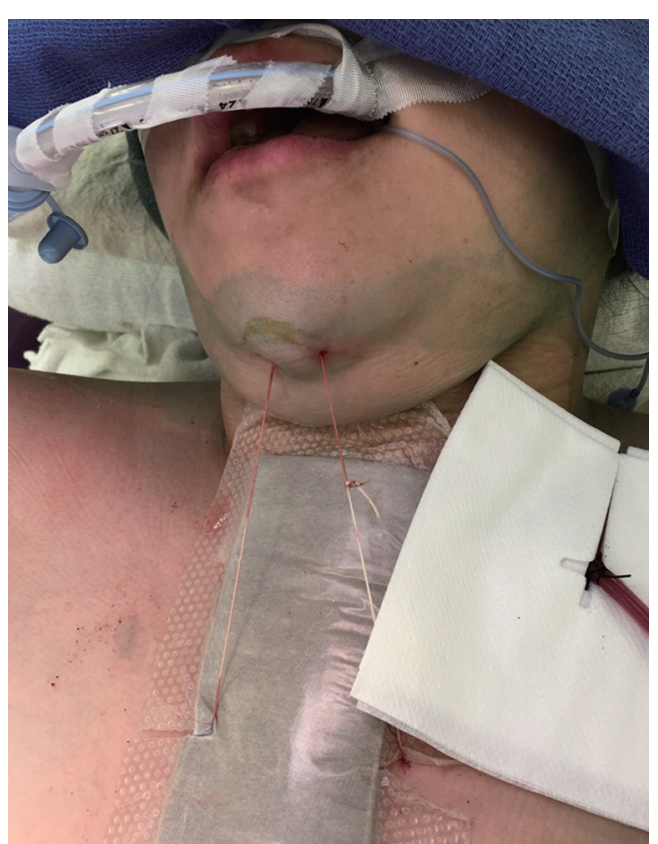

Figure 9 Maintenance of neck flexion with Grillo stitch.

\section{Carinal resection after previous pneumonectomy}

Re-do carinal resections are rarely possible and very uncommon. Either positive margins during recent resection or recurrence after previous resection might necessitate consideration for the redo procedure with carinal resection. Most of these interventions can be accomplished through right thoracotomy. Loss of tissue planes and dissection in the reoperative field challenges surgeon's skills. These procedures naturally carry elevated surgical risk and careful planning and preoperative evaluation is mandatory $(2,46)$.

\section{Postop management}

Stress of the positive pressure ventilation on the anastomosis can compromise airway healing. As such, these patients should be extubated as early as possible, preferably in the operating room. Airway division and anastomosis results in the disruption of mucociliary clearance, resulting in retention of secretions, respiratory distress and pneumonia. Adequate pain control, early mobilization, aggressive respiratory therapy and liberal use of bronchoscopy for clearance of secretions are required for successful care of this extremely challenging patient population $(46,48,60)$.

Neck flexion is maintained postoperatively for a week after surgery with "G" stitch ("guardian" or Grillo), applied between chin and presternal tissue (Figure 9). However, in some authors' opinion use of the stitch is not mandatory and neck flexion can be maintained by simply adding an extra pillow for a few days $(25,33,46)$.

With any concern of the anastomotic integrity timely diagnostic bronchoscopy and early intervention is paramount. Bronchoscopy is routinely performed prior to discharge to assure anastomotic condition $(2,60,61)$.

\section{Early postoperative complication}

Pulmonary edema and ARDS are feared complications of early postoperative period with mortality approaching $50 \%$. Etiology of this condition remains elusive, however fluid overload has been implemented in the pathogenesis. Supportive care with oxygen supplementation, ventilatory support, fluid restriction and diuresis has been used with relative success. Steroids should be used cautiously for the concern of negative impact on the anastomosis healing $(62,63)$.

Cardiac arrhythmias, especially atrial fibrillation is common after thoracic surgical interventions. Development of the arrhythmia has been associated with anastomotic problems, at least in the esophageal surgery. Rate and rhythm control usually achieved with beta-blockers, calcium channel blockers and amiodarone. Anticoagulation can be started when is deemed safe from surgical standpoint (64-66).

Vocal cord paralysis is rarely explicitly described and is more common in higher levels of resection. However, its presence increasing risk of aspiration, a potentially fatal event, especially in pneumonectomy patients. Bilateral vocal cord paralysis can end up in permanent tracheostomy $(25,46,67)$.

Anastomotic complication may range from granulations, mild mucosal necrosis to various degree of the dehiscence. Dehiscence is the most feared complication of the airway surgery, leading to mediastinitis and potential loss of airway. Sometimes tissue flap can contain the leak and protect mediastinum from contamination. Individual management in this scenario is required. Covered airway stents can sometimes be utilized. In case of bronchopleural fistula development, prognosis is poor and this condition requires prompt and individualized approaches $(48,49,51,53,68)$.

\section{Late complications}

Tumor recurrence. Negative intraoperative margins of 
resection are required for the best outcome. Malignant involvement of the margin increases risk of local recurrence. Adenoid cystic carcinoma has tendency for submucosal and perineural spread beyond visible borders and frequently is associated with positive margins $(1,69)$. Repeat surgical resection is rarely possible. Recurrence is usually managed with endoluminal palliation with ablative techniques, brachytherapy and stenting. Systemic therapy and radiation are also used $(14,69,70)$.

Postoperative anastomotic strictures are difficult problem to manage and develop in response to granulation or anastomotic dehiscence. Dilation, laser ablation and stenting usually can be used to palliate the obstruction. Resection and re-anastomosis is rarely possible. Some patients require maintenance of the airway with tracheostomy or T-tubes $(7,11,46,70)$.

\section{Outcomes}

Central airway resection and reconstruction is a challenging surgical problem, requiring considerable expertise and technical excellence. Complication rates are ranging from $10 \%$ to $50 \%$ in published series and mortality ranges from $7 \%$ to $29 \%$. In oncologic cases long term survival for carinal resection depends on the lymph node status and ranges from $51 \%$ in N0, to $32 \%$ in $\mathrm{N} 1$ and $12 \% \mathrm{~N} 2$ survival $(2,4,15-19)$.

\section{Acknowledgments}

Funding: None.

\section{Footnote}

Provenance and Peer Review: This article was commissioned by the Guest Editors (Alper Toker and Alan Sihoe) for the series "Extended resections for lung cancer" published in Shanghai Chest. The article has undergone external peer review.

Conflicts of Interest: All authors have completed the ICMJE uniform disclosure form (available at http://dx.doi. org/10.21037/shc.2018.10.03). The series "Extended resections for lung cancer" was commissioned by the editorial office without any funding or sponsorship. Dr. Petrov reports Speaker Fees from Veran Medical, outside the submitted work. The authors have no other conflicts of interest to declare.

Ethical Statement: The authors are accountable for all aspects of the work in ensuring that questions related to the accuracy or integrity of any part of the work are appropriately investigated and resolved.

Open Access Statement: This is an Open Access article distributed in accordance with the Creative Commons Attribution-NonCommercial-NoDerivs 4.0 International License (CC BY-NC-ND 4.0), which permits the noncommercial replication and distribution of the article with the strict proviso that no changes or edits are made and the original work is properly cited (including links to both the formal publication through the relevant DOI and the license). See: https://creativecommons.org/licenses/by-nc-nd/4.0/.

\section{References}

1. Junker K. Pathology of tracheal tumors. Thorac Surg Clin 2014;24:7-11.

2. Grillo HC. Carinal reconstruction. Ann Thorac Surg 1982;34:356-73.

3. Mathisen DJ, Grillo HC. Carinal resection for bronchogenic carcinoma. J Thorac Cardiovasc Surg 1991;102:16-22; discussion 22-3.

4. Dartevelle PG, Mitilian D, Fadel E. Extended surgery for T4 lung cancer: a 30 years' experience. Gen Thorac Cardiovasc Surg 2017;65:321-8.

5. Natkunam R, Tse CY, Ong BH, et al. Carinal resection for stenotic tuberculous tracheitis. Thorax 1988;43:492-3.

6. Perelman M, Koroleva N. Surgery of the trachea. World J Surg 1980;4:583-91.

7. Murgu SD, Egressy K, Laxmanan B, et al. Central Airway Obstruction: Benign Strictures, Tracheobronchomalacia, and Malignancy-related Obstruction. Chest 2016;150:426-41.

8. Bhattacharyya N. Contemporary staging and prognosis for primary tracheal malignancies: a population-based analysis. Otolaryngol Head Neck Surg 2004;131:639-42.

9. He J, Shen J, Huang J, et al. Prognosis of primary tracheal tumor: A population-based analysis. J Surg Oncol 2017;115:1004-10.

10. Macchiarini P, Altmayer M, Go T, et al. Technical innovations of carinal resection for nonsmall-cell lung cancer. Ann Thorac Surg 2006;82:1989-97; discussion 1997.

11. Folch E, Keyes C. Airway stents. Ann Cardiothorac Surg 
2018;7:273-83.

12. Shin JH, Kim SW, Shim TS, et al. Malignant tracheobronchial strictures: palliation with covered retrievable expandable nitinol stent. J Vasc Interv Radiol 2003;14:1525-34.

13. Lee P, Kupeli E, Mehta AC. Airway stents. Clin Chest Med 2010;31:141,50, Table of Contents.

14. Petrella F, Borri A, Casiraghi M, et al. Operative rigid bronchoscopy: indications, basic techniques and results. Multimed Man Cardiothorac Surg 2014;2014.

15. Glover J, Velez-Cubian FO, Toosi K, et al. Perioperative outcomes and lymph node assessment after induction therapy in patients with clinical N1 or N2 non-small cell lung cancer. J Thorac Dis 2016;8:2165-74.

16. Brea TP, Ravina AR, Villamor JMC, et al. Use of Magnetic Resonance Imaging for N-Staging in Patients with NonSmall Cell Lung Cancer. A Systematic Review. Arch Bronconeumol 2018. [Epub ahead of print].

17. Citak N, Buyukkale S, Sayar A, et al. Prognostic factors and survival in patients undergoing surgery for T4 nonsmall cell lung carcinoma. Acta Chir Belg 2014;114:17-24.

18. Jensik RJ, Faber LP, Kittle CF, et al. Survival in patients undergoing tracheal sleeve pneumonectomy for bronchogenic carcinoma. J Thorac Cardiovasc Surg 1982;84:489-96.

19. Faber LP. Results of surgical treatment of stage III lung carcinoma with carinal proximity. The role of sleeve lobectomy versus pneumonectomy and the role of sleeve pneumonectomy. Surg Clin North Am 1987;67:1001-14.

20. Hegde PV, Liberman M. Mediastinal Staging: Endosonographic Ultrasound Lymph Node Biopsy or Mediastinoscopy. Thorac Surg Clin 2016;26:243-9.

21. El-Barhoun EN, Chew G, Crouch B, et al. Reproducibility of a semi-quantitative lobar pulmonary ventilation and perfusion technique using SPET and CT. Hell J Nucl Med 2017;20:71-5.

22. Periyakoil VS. Frailty as a terminal illness. Am Fam Physician 2013;88:363-8.

23. Ginsberg RJ. Carinal Resection and Sleeve Pneumonectomy Using a Transsternal Approach. Oper Tech Thorac Cardiovasc Surg 1998;3:203-16.

24. El-Baz N, El-Ganzouri A, Gottschalk W, et al. Onelung high-frequency pressure ventilation for sleeve pneumonectomy: an alternative technique. Anesth Analg 1981;60:683-6.

25. Friedel G, Kyriss T, Leitenberger A, et al. Longterm results after 110 tracheal resections. Ger Med Sci
2003;1:Doc10.

26. Perera ER, Vidic DM, Zivot J. Carinal resection with two high-frequency jet ventilation delivery systems. Can J Anaesth 1993;40:59-63.

27. Peng G, Cui F, Ang KL, et al. Non-intubated combined with video-assisted thoracoscopic in carinal reconstruction. J Thorac Dis 2016;8:586-93.

28. Fitzsimons $\mathrm{MG}, \mathrm{Ng} \mathrm{J}$, Wright C, et al. Carinal resection requiring cardiopulmonary bypass in a pregnant patient. Ann Thorac Surg 2013;96:1085-7.

29. Horita K, Itoh T, Furukawa K, et al. Carinal reconstruction under veno-venous bypass using a percutaneous cardiopulmonary bypass system. Thorac Cardiovasc Surg 1996;44:46-9.

30. Keeyapaj W, Alfirevic A. Carinal resection using an airway exchange catheter-assisted venovenous ECMO technique. Can J Anaesth 2012;59:1075-6.

31. Redwan B, Ziegeler S, Freermann S, et al. Intraoperative veno-venous extracorporeal lung support in thoracic surgery: a single-centre experience. Interact Cardiovasc Thorac Surg 2015;21:766-72.

32. Jyoti A, Maheshwari A, Shivnani G, et al. Management of a case of left tracheal sleeve pneumonectomy under cardiopulmonary bypass: anesthesia perspectives. Ann Card Anaesth 2014;17:62-6.

33. Hecker E, Volmerig J. Extended tracheal resections. Thorac Surg Clin 2014;24:85-95.

34. Hachey KJ, Digesu CS, Armstrong KW, et al. A novel technique for tumor localization and targeted lymphatic mapping in early-stage lung cancer. J Thorac Cardiovasc Surg 2017;154:1110-8.

35. Schweiger T, Schwarz S, Traxler D, et al. Bronchoscopic Indocyanine Green Fluorescence Imaging of the Anastomotic Perfusion After Tracheal Surgery. Ann Thorac Surg 2016;101:1943-9.

36. Maniwa Y. Surgical treatment of air way disease. J Thorac Dis 2016;8:E78-82.

37. Gonzalez-Rivas D, Yang Y, Sekhniaidze D, et al. Uniportal video-assisted thoracoscopic bronchoplastic and carinal sleeve procedures. J Thorac Dis 2016;8:S210-22.

38. Yin R, Qiu N, Zhu J, et al. Video-assisted left main bronchial carcinoma resection and secondary carinal reconstruction. J Thorac Cardiovasc Surg 2013;145:e60-2.

39. Xu X, Chen H, Yin W, et al. Thoracoscopic half carina resection and bronchial sleeve resection for central lung cancer. Surg Innov 2014;21:481-6.

40. Chakaramakkil MJ, Jim LY, Soon JL, et al. Continuous 
absorbable suture technique for tracheobronchial sleeve resections. Asian Cardiovasc Thorac Ann 2011;19:44-7.

41. Tan GJS, Ooi WM, Law RHF, et al. Robotic pericardial patch repair of the bronchus intermedius after bronchogenic cyst removal. Interact Cardiovasc Thorac Surg 2018;26:711-2.

42. Nakagawa T, Chiba N, Ueda Y, et al. Clinical experience of sleeve lobectomy with bronchoplasty using a continuous absorbable barbed suture. Gen Thorac Cardiovasc Surg 2015;63:640-3.

43. Atallah I, Aldkhyyal A, Castellanos PF. Modified singlestage segmental cricotracheal resection. Eur Arch Otorhinolaryngol 2018;275:139-46.

44. Blasberg JD, Wright CD. Surgical considerations in tracheal and carinal resection. Semin Cardiothorac Vasc Anesth 2012;16:190-5.

45. Grillo HC, Mathisen DJ. Primary tracheal tumors: treatment and results. Ann Thorac Surg 1990;49:69-77.

46. Mutrie CJ, Eldaif SM, Rutledge CW, et al. Cervical tracheal resection: new lessons learned. Ann Thorac Surg 2011;91:1101-6; discussion 1106.

47. Grillo HC, Mathisen DJ, Wain JC. Management of tumors of the trachea. Oncology (Williston Park) 1992;6:61-7; discussion 68, 70, 72 .

48. Wright CD, Grillo HC, Wain JC, et al. Anastomotic complications after tracheal resection: prognostic factors and management. J Thorac Cardiovasc Surg 2004;128:731-9.

49. Arnold PG, Pairolero PC. Intrathoracic muscle flaps. An account of their use in the management of 100 consecutive patients. Ann Surg 1990;211:656-60; discussion 660-2.

50. Blatter J, Krueger T, Ris HB, et al. Complex Tracheocarinal Reconstructions Using Extrathoracic Muscle Flaps as Airway Substitutes. Ann Thorac Surg 2018;105:1492-8.

51. Fricke A, Bannasch H, Klein HF, et al. Pedicled and free flaps for intrathoracic fistula management. Eur J Cardiothorac Surg 2017;52:1211-7.

52. Serna-Gallegos DR, McKenna RJ Jr. Video-Assisted Intercostal Muscle Flaps for Bronchial Stump Coverage. Ann Thorac Surg 2017;103:e215-7.

53. Müller LC, Abendstein B, Salzer GM. Use of the greater omentum for treatment and prophylaxis of anastomotic and stump dehiscence in major airway surgery. Thorac Cardiovasc Surg 1992;40:323-5.

54. Abouarab AA, Elsayed HH, Elkhayat H, et al. Current Solutions for Long-Segment Tracheal Reconstruction.
Ann Thorac Cardiovasc Surg 2017;23:66-75.

55. Hasse J. Patch-closure of tracheal defects with pericardium/PTFE. A new technique in extended pneumonectomy with carinal resection. Eur J Cardiothorac Surg 1990;4:412-5; discussion 416.

56. Fabre D, Kolb F, Fadel E, et al. Successful tracheal replacement in humans using autologous tissues: an 8-year experience. Ann Thorac Surg 2013;96:1146-55.

57. Bhora FY, Lewis EE, Rehmani SS, et al. Circumferential Three-Dimensional-Printed Tracheal Grafts: Research Model Feasibility and Early Results. Ann Thorac Surg 2017;104:958-63.

58. Best CA, Pepper VK, Ohst D, et al. Designing a tissueengineered tracheal scaffold for preclinical evaluation. Int J Pediatr Otorhinolaryngol 2018;104:155-60.

59. Den Hondt M, Vranckx JJ. Reconstruction of defects of the trachea. J Mater Sci Mater Med 2017;28:24.

60. Leuzzi G, Facciolo F, Pastorino U, et al. Methods for the postoperative management of the thoracic oncology patients: lessons from the clinic. Expert Rev Respir Med 2015;9:751-67.

61. Kawagoe I, Inada E, Ishikawa S, et al. Perioperative management of carinal pneumonectomy: a retrospective review of 13 patients. J Anesth 2015;29:446-9.

62. Evans RG, Naidu B. Does a conservative fluid management strategy in the perioperative management of lung resection patients reduce the risk of acute lung injury? Interact Cardiovasc Thorac Surg 2012;15:498-504.

63. Kometani T, Okamoto T, Yoshida S, et al. Acute respiratory distress syndrome after pulmonary resection. Gen Thorac Cardiovasc Surg 2013;61:504-12.

64. Riber LP, Larsen TB, Christensen TD. Postoperative atrial fibrillation prophylaxis after lung surgery: systematic review and meta-analysis. Ann Thorac Surg 2014;98:1989-97.

65. Berry MF, D'Amico TA, Onaitis MW. Use of amiodarone after major lung resection. Ann Thorac Surg 2014;98:1199-206.

66. Zhao BC, Huang TY, Deng QW, et al. Prophylaxis Against Atrial Fibrillation After General Thoracic Surgery: Trial Sequential Analysis and Network Meta-Analysis. Chest 2017;151:149-59.

67. Auchincloss HG, Wright CD. Complications after tracheal resection and reconstruction: prevention and treatment. J Thorac Dis 2016;8:S160-7.

68. Sanli M, Arslan E, Isik AF, et al. Carinal sleeve pneumonectomy for lung cancer. Acta Chir Belg 2013;113:258-62. 
69. Sawabata N, Maeda H, Matsumura A, et al. Clinical implications of the margin cytology findings and margin/ tumor size ratio in patients who underwent pulmonary excision for peripheral non-small cell lung cancer. Surg

doi: $10.21037 /$ shc.2018.10.03

Cite this article as: Petrov RV, Bakhos CT, Abbas AE. Carinal resection. Shanghai Chest 2018;2:84.
Today 2012;42:238-44.

70. Chakraverty SC, Rafferty PR. Laser therapy for endobronchial tumours. Scott Med J 1992;37:141-3. 